\title{
New 2, 2-Dichloroacetamidines with Heterocyclic Fragments
}

\author{
PAVLO V. ZADOROZHNI", IHOR O. POKOTYLO, \\ VADYM V. KISELEV and ALEKSANDR V. KHARCHENKO
}

Department of Organic Substances and Pharmaceutical Preparations, Ukrainian State University of Chemical Technology, Gagarin Ave., 8, Dnipro 49005, Ukraine torfp@i.ua

Received 19 July 2016 / Accepted 3 September 2016

\begin{abstract}
Based on easily available $N$-amidoalkylated derivatives of 2-aminobenzimidazole, 2aminobenztiazole and 2-amino-1,3,4-oxadiazole, reacting with an excess of highly basic amines, corresponding $N$-hetaryl-2,2-dichloroacetamidines were obtained. The reaction proceeds in anhydrous dioxane and is followed by dehydrochlorination of substrate and replacing therein the amide moiety with an amine one. The structures of the synthesized compounds have been fully characterized by IR, ${ }^{1} \mathrm{H}$ NMR spectroscopy, mass spectrometric data and elemental analysis.
\end{abstract}

Keywords: Hetarylamidine, Benzimidazole, Benzthiazole, 1,3,4-Oxadiazole.

\section{Introduction}

Amidines form the most important class of organic compounds. Amidine moiety is very common in the structure of biologically active natural compounds: alkaloids ${ }^{1-4}$, antibiotics ${ }^{5}$, pigments $^{6}$; it is actively involved in metabolism, allowing to create of a number of effective drugs $^{7}$, remedies and plant growth stimulants ${ }^{8}$ on its basis. These compounds are extremely promising as substrates ${ }^{9}$ and the catalysts ${ }^{10}$ for the synthesis of organic substances of varying degrees of complexity. In addition, they have found wide application in biological studies as fluorescent markers ${ }^{11}$. Amidines with heterocyclic fragments are of particular interest ${ }^{12-19}$.

Earlier, it was shown that by means of simple transformations it was possible to obtain corresponding $\mathrm{N}$-hetaryl-2,2-dichloroacetamidines (2) out of $\mathrm{N}$-amidoalkylated derivatives of 2-amino-5-aryl-1,3,4-oxadiazole and 2-aminobenzoxazole (1) (Scheme 1) ${ }^{20}$.

The fact that in the same conditions $\mathrm{N}$-amidoalkylated derivatives of 2-amino-5-aryl1,3,4-thiadiazole give the corresponding imidazo[2,1-b][1,3,4]thiadiazoles $(3)^{21,22}$ points to the non-universality of the open reaction.

In order to enlarge chemical libraries of multipurpose azaheterocycles for pharmaceutical industry and to study the transformations scope, taking place on the scheme 1 , we have expanded the range of the initial $\mathrm{N}$-amidoalkylated heterocycles. On the one hand, 
the obtained compounds are of interest as promising reagents for heterocyclizations and on the other hand as potential biologically active substances.

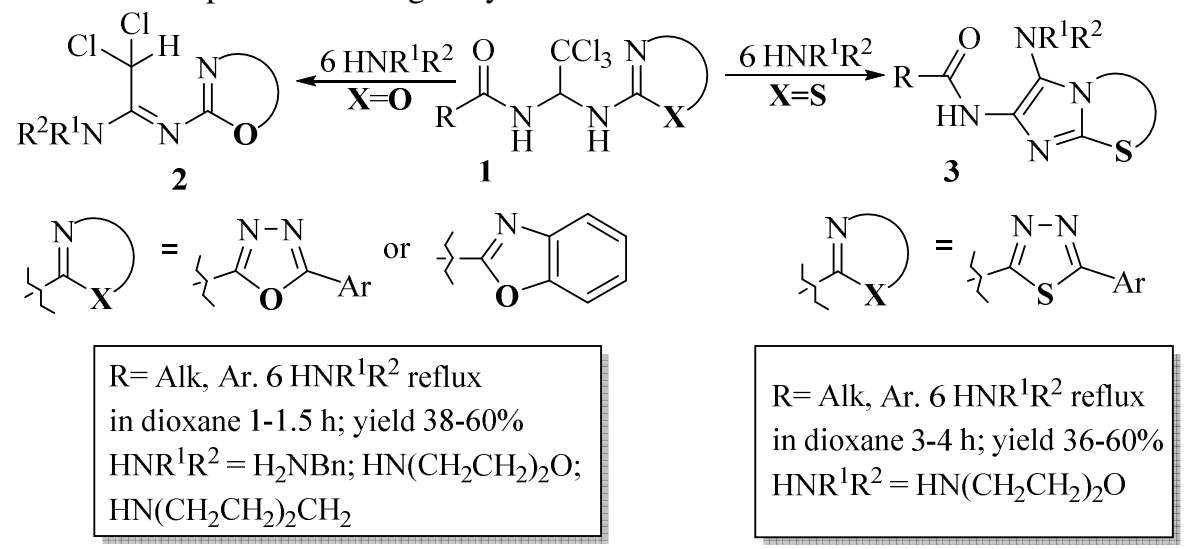

Scheme 1. Formation of $N$-hetaryl-2,2-dichloroacetamidines and imidazo[2,1- $b][1,3,4]$ thiadiazoles derivatives

\section{Experimental}

The melting point was determined in open capillaries and was not corrected. IR spectra were recorded in $\mathrm{KBr}$ tablets using the device Spectrum BX II, mass spectra - the device VG7070, desorption of ions from solution samples in meta-nitrobenzyl alcohol being conducted by beam of argon atoms with $8 \mathrm{keV}$ energy. ${ }^{1} \mathrm{H}$ NMR spectra were measured on spectrometer Varian VXR-200 (standard TMS). Chemical shifts $(\delta)$ were given in ppm downfield. Monitoring of the reaction progress and identity of the compounds obtained was performed by TLC (Silufol UV-254, eluent - chloroform: acetone - 3:1).

General procedure for the synthesis of $N$-benzimidazo-2,2-dihloroacetamidines (5a-c)

$10 \mathrm{mmol}$ of one of the compounds $N$-amidoalkylated derivatives of 2-aminobenzimidazole $(4)^{23,24}$ and $50 \mathrm{mmol}$ of the appropriate amine in $20-25 \mathrm{~mL}$ of dioxane were being refluxed for 33.5 hours. During the reaction, the solution acquired brown color and corresponding amine hydrochloride crystals precipitated from the reaction mixture. After the reaction the mixture was cooled to room temperature, the precipitate was filtered, washed with $2-3 \mathrm{~mL}$ of dioxane, and the solvent was removed in vacuo and the residue was recrystallized from ethanol (96\%).

\section{(1E)-N'-1H-Benzimidazol-2-yl-N-benzyl-2,2-dichloroethanimidamide (5a)}

Yield $24 \%(0.80 \mathrm{~g})$, white crystals, mp. $152-154{ }^{\circ} \mathrm{C} . \mathrm{R}_{\mathrm{f}}=0.75 . \mathrm{NMR}^{1} \mathrm{H}(200 \mathrm{MHz}$, DMSOd6), $\delta$, ppm.: 11.25 (s, 1H, NH), 9.14 (prs, $1 \mathrm{H}, \mathrm{NH}), 8.37$ (s, 1H, $\left.\mathrm{CHCl}_{2}\right), 7.36-7.09(\mathrm{~m}, 9 \mathrm{H}$, Arom.), 4.60 (prs, 2H, CH ). IR-spectra, $\mathrm{cm}^{-1}: 3244,3018,1631,1527,1489,1418,1317$, 1284, 1089, 813. Found (\%): $\mathrm{C} 57.63, \mathrm{H} 4.30, \mathrm{Cl} 21.32, \mathrm{~N}$ 16.83. Anal. Calcd. for $\mathrm{C}_{16} \mathrm{H}_{14} \mathrm{Cl}_{2} \mathrm{~N}_{4}$ (\%): C 57.67; H 4.23; $\mathrm{Cl} 21.28 ; \mathrm{N}$ 16.81. MC (FAB, $\left.m / z\right): 333[\mathrm{M}+\mathrm{H}]^{+}$.

$N$-[(1E)-2,2-Dichloro-1-morpholin-4-ylethylidene]-1H-benzimidazol-2-amine (5b)

Yield $21 \%$ (0.66 g), white crystals, mp. $172-174{ }^{\circ} \mathrm{C} . \mathrm{R}_{\mathrm{f}}=0.74$. NMR ${ }^{1} \mathrm{H}(200 \mathrm{MHz}, \mathrm{DMSO}-$ d6), $\delta$, ppm.: 11.89 (s, 1H, NH), 8.79 (s, $1 \mathrm{H}, \mathrm{CHCl}_{2}$ ), 7.54-7.02 (m, 4H, Arom.), 3.87-3.73 (m, 8H, Morph.). IR-spectra, $\mathrm{cm}^{-1}: 3252,3022,1629,1533,1499,1421,1319,1287,1092$, 827. Found (\%):C 49.82; $\mathrm{H} 4.53 ; \mathrm{Cl} 22.67 ; \mathrm{N}$ 17.93. Anal. Calcd. for $\mathrm{C}_{13} \mathrm{H}_{14} \mathrm{Cl}_{2} \mathrm{~N}_{4} \mathrm{O}(\%)$ : $\mathrm{C}$ 49.86; H 4.51; $\mathrm{Cl} 22.64 ; \mathrm{N}$ 17.89. MC (FAB, $m / z): 313[\mathrm{M}+\mathrm{H}]^{+}$. 
$N$-[(1E)-2,2-Dichloro-1-piperidin-1-ylethylidene]-1H-benzimidazol-2-amine (5c)

Yield $32 \%(0.99 \mathrm{~g})$, white crystals, mp. $162-164{ }^{\circ} \mathrm{C} . \mathrm{R}_{\mathrm{f}}=0.70 . \mathrm{NMR}{ }^{1} \mathrm{H}(200 \mathrm{MHz}$, DMSOd6), $\delta$, ppm.: 11.89 (s, 1H, NH), 8.76 (s, $1 \mathrm{H}, \mathrm{CHCl}_{2}$ ), 7.30-7.05 (m, 4H, Arom.), 3.83, 1.66 (m, 10H, Piper.). IR-spectra, $\mathrm{cm}^{-1}: 3356,3318,2920,2900,1583,1441,1409,1376,1247,1120$, 959, 783, 744. Found (\%):C 54.05; H 5.16; Cl 22.79; N 18.00. Anal. Calcd. for $\mathrm{C}_{14} \mathrm{H}_{16} \mathrm{Cl}_{2} \mathrm{~N}_{4}$ (\%): C 54.03; H 5.18; Cl 22.78; N 18.00. MC (FAB, $m / z): 312[\mathrm{M}+\mathrm{H}]^{+}$.

Synthesis methods of N-[(1E)-2,2-dichloro-1-morpholin-4-ylethylidene]-1,3benzothiazol-2-amine (8)

$10 \mathrm{mmol}$ of Compound $\mathrm{N}$-amidoalkylated derivatives of 2 -aminobenzthiazole $(\mathbf{6})^{23}$ and 50 mmol of morpholine in $20-25 \mathrm{~mL}$ of dioxane were being refluxed for 1.5 hours, the mixture was cooled to room temperature, the precipitate was filtered, washed with $2-3 \mathrm{~mL}$ of dioxane, and the solvent was removed in vacuo and the residue was recrystallized from ethanol $(65 \%)$. Yield $27 \%(0.89 \mathrm{~g})$, white crystals, mp. $125-126{ }^{\circ} \mathrm{C} . \mathrm{R}_{\mathrm{f}}=0.78 . \mathrm{NMR}{ }^{1} \mathrm{H}(200 \mathrm{MHz}$, DMSOd6), $\delta$, ppm.: 8.73 (s, 1H, $\mathrm{CHCl}_{2}$ ), 7.88-7.24 (m, 4H, Arom.), 3.86-3.74 (m, 8H, Morph.). IRspectra, $\mathrm{cm}^{-1}: 3008,1622,1572,1492,1421,1349,1262,1278,1132,1087,835$. Found (\%):C 47.29; H 3.95; $\mathrm{Cl} 21.51 ; \mathrm{N} 12.75 ; \mathrm{S} 9.70$. Anal. Calcd. for $\mathrm{C}_{13} \mathrm{H}_{13} \mathrm{Cl}_{2} \mathrm{~N}_{3} \mathrm{OS}(\%)$ : C 47.28; $\mathrm{H}$ 3.97; $\mathrm{Cl} 21.47 ; \mathrm{N} 12.72 ; \mathrm{S} 9.71$. MC (FAB, $m / z): 330[\mathrm{M}+\mathrm{H}]^{+}$.

Synthesis methods of $N$-[(1E)-2,2-dichloro-1-morpholin-4-ylethylidene]-5-phenyl1,3,4-oxadiazol-2-amine (10a) and its analogues $(\mathbf{1 0 b}, \mathrm{c})$

10 mmol of Compound 4-methyl- $N$-(2,2,2-trichloro-1-((5-phenyl-1,3,4-oxadiazol-2yl)amino)ethyl)benzamide (9a) ${ }^{25}$ and $50 \mathrm{mmol}$ of morpholine in $20-25 \mathrm{~mL}$ of dioxane were being refluxed for 1.5 hours, the mixture was cooled to room temperature, the precipitate was filtered, washed with $2-3 \mathrm{~mL}$ of dioxane, the solvent was removed in vacuo and the residue was recrystallized from ethanol $(65 \%)$. Yield $51 \%(1.74 \mathrm{~g})$, white crystals, mp. 134$136{ }^{\circ} \mathrm{C} . \mathrm{R}_{\mathrm{f}}=0.64 . \mathrm{NMR}{ }^{1} \mathrm{H}(200 \mathrm{MHz}, \mathrm{DMSO}-\mathrm{d} 6), \delta$, ppm.: 7.92-7.89 (m, 2H, Ph), 7.80 (s, $1 \mathrm{H}, \mathrm{CHCl}_{2}$ ), 7.56-7.53 (m, 3H, Ph), 3.91-3.74 (m, 8H, Morph.). IR-spectra, $\mathrm{cm}^{-1}: 3002$, 2994, 1602, 1533, 1445, 1363, 1258, 1178, 1115, 1025, 986, 784, 734. Found (\%):C 49.29; $\mathrm{H}$ 4.18; $\mathrm{Cl} 20.82 ; \mathrm{N} \mathrm{16.40.} \mathrm{Anal.} \mathrm{Calcd.} \mathrm{for} \mathrm{C}_{14} \mathrm{H}_{14} \mathrm{Cl}_{2} \mathrm{~N}_{4} \mathrm{O}_{2}$ (\%): C 49.28; $\mathrm{H} 4.14 ; \mathrm{Cl} 20.78$; $\mathrm{N}$ 16.42. MC $(\mathrm{FAB}, \mathrm{m} / z): 342[\mathrm{M}+\mathrm{H}]^{+}$.

$N$-[(1E)-2,2-Dichloro-1-morpholin-4-ylethylidene]-5-(2-nitrophenyl)-1,3,4oxadiazol-2-amine (10b)

Yield $35 \%$ (1.35 g), white crystals, mp. $174-175^{\circ} \mathrm{C} . \mathrm{R}_{\mathrm{f}}=0.70 . \mathrm{NMR}^{1} \mathrm{H}(200 \mathrm{MHz}$, DMSOd6), $\delta$, ppm.: 7.92-7.89 (m, 2H, Arom.), 7.80 (s, 1H, $\mathrm{CHCl}_{2}$ ), 7.56-7.53 (m, 2H, Arom.), 3.913.74 (m, 8H, Morph.). IR-spectra, $\mathrm{cm}^{-1}:$ 3002, 2994, 1602, 1533, 1445, 1363, 1258, 1178, $1115,1025,986,784,734$. Found (\%):C 43.52; H 3.35; Cl 18.40; N 18.17. Anal. Calcd. for $\mathrm{C}_{14} \mathrm{H}_{13} \mathrm{Cl}_{2} \mathrm{~N}_{5} \mathrm{O}_{4}(\%): \mathrm{C} 43.54 ; \mathrm{H} 3.39 ; \mathrm{Cl} 18.36 ; \mathrm{N}$ 18.13. MC (FAB, $\left.m / z\right): 387[\mathrm{M}+\mathrm{H}]^{+}$.

$N$-[(1E)-2,2-Dichloro-1-morpholin-4-ylethylidene]-5-(4-nitrophenyl)-1,3,4oxadiazol-2-amine (10c)

Yield $24 \%$ (0.93 g), white crystals, mp. $175-177{ }^{\circ} \mathrm{C} . \mathrm{R}_{\mathrm{f}}=0.66 . \mathrm{NMR}{ }^{1} \mathrm{H}(200 \mathrm{MHz}$, DMSOd6), $\delta$, ppm.: 7.92-7.89 (m, 2H, Arom.), 7.80 (s, 1H, $\mathrm{CHCl}_{2}$ ), 7.56-7.53 (m, 2H, Arom.), 3.91-3.74 (m, 8H, Morph.). IR-spectra, $\mathrm{cm}^{-1}:$ 3002, 2994, 1602, 1533, 1445, 1363, 1258, 1178, 1115, 1025, 986, 784, 734. Found (\%):C 43.53; H 3.36; Cl 18.41; N 18.15. Anal. Calcd. for $\mathrm{C}_{14} \mathrm{H}_{13} \mathrm{Cl}_{2} \mathrm{~N}_{5} \mathrm{O}_{4}$ (\%): C 43.54; $\mathrm{H} 3.39 ; \mathrm{Cl} 18.36 ; \mathrm{N}$ 18.13. $\mathrm{MC}(\mathrm{FAB}, \mathrm{m} / z): 387$ $[\mathrm{M}+\mathrm{H}]^{+}$. 


\section{Results and Discussion}

Detailed studies of reactions of $N$-amidoalkylated derivatives (4) of 2-aminobenzimidazole ${ }^{22,23}$ with excess of primary and secondary amines have shown that in all cases the transformation is accompanied by simultaneous replacement of the amide moiety to amine residue, and by dehydrochlorination with formation of the corresponding hetarylamidines (5), as expected (Scheme 2).

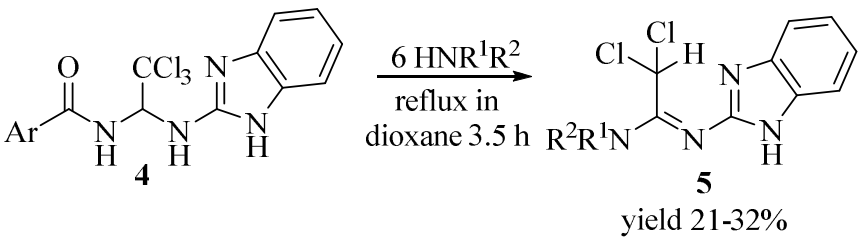

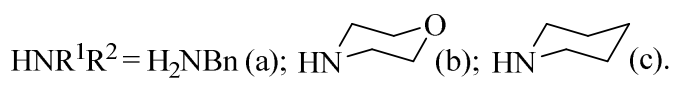

Scheme 2. Formation of $N$-benzimidazo-2,2-dichloroacetamidines

Transformation $\mathbf{4} \rightarrow \mathbf{5}$ is similar to that described previously ${ }^{20}$, but is much slower and it is required not less than 3-3.5 hours to complete the reaction. At the same time, the products 5 are hardly isolated from the reaction mixture, which significantly reduces their outputs compared to benzoxazole analogues.

It has been assumed that $N$-amidoalkylated derivatives (6) of 2-aminobenzthiazoles ${ }^{23}$ with excess morpholine will interact like thiadiazole analogs (Scheme 1), forming the corresponding tricyclic systems (7) (Scheme 3). However, it is only amidine (8) that has been isolated from the reaction mixture.

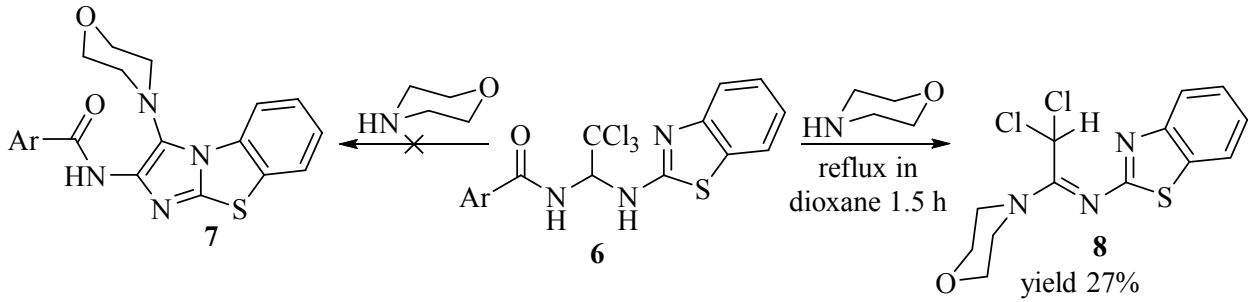

Scheme 3. Formation of $N$-[(1E)-2,2-dichloro-1-morpholin-4-ylethylidene]-1,3-benzothiazol-2amine (8)

It is obvious that the nature of heteroatom is not a key factor in the direction of data transformations. It has been suggested that electrophilic properties of heterocycle play the primary role in them. Therefore, the reaction with morpholine is introduced with $\mathrm{N}$-amidoalkylated derivatives of 2-amino-1,3,4-oxadiazole (9) with electrophilic substituents at position 5 (Scheme 4). But even in this case, the reaction occurs with the formation of only amidines $\mathbf{1 0}$.

There are no absorption bands of stretching vibrations of the $\mathrm{C}=\mathrm{O}$ in IR spectra of compounds 5, 8, 10 in the frequency range $1720-1630 \mathrm{~cm}^{-1}$, which confirms the replacement of the amide moiety to amine residue, and in ${ }^{1} \mathrm{H}$ NMR spectra in the region of 7.80-8.79 $\mathrm{ppm}$ there is singlet signal of dichloromethyl group proton. Because of the high lability of compounds 5, 8, 10, mass spectra of electron impact (EI) have been uninformative, the intensity of the molecular ion peak not exceeding $1.0 \%$, and for some compounds molecular ion peak not being observed at all. FAB spectra have turned to be more informative. 
<smiles>CCOCCNC(=O)NC(Nc1nnc([Al])o1)C(Cl)(Cl)Cl</smiles><smiles>COCCN(CCO)/C(=N/c1nnc([Al])o1)C(Cl)Cl</smiles>

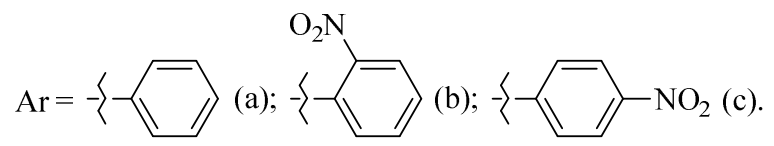

Scheme 4. Formation of $N$-1,34-oxadiazolo-2,2-dichloroacetamidines

As has already been suggested ${ }^{20}$, it is likely that there is dehydrochlorination in the first stage in the process, and the resulting $N$-(1-hetaryl-2,2-dichlorovinyl)carboxamide (11) becomes stabilized in (E)- $N$-(1-hetaryl-2,2-dichloroethyl)carboxamide (12) by an intramolecular hydrogen bond followed by the addition of amine to the $\mathrm{C}=\mathrm{N}$ linkages and elimination of the amide moiety. At the same time, due to spatial complications created by $\mathrm{CHCl}_{2}$ group, the amine attack of electrophilic center should take place on the opposite, regarding to its position side (Scheme 5). This explains the trans-stereoselectivity of this reaction.<smiles>[R]C(=O)NC(NC1=NCCC[X]1)C(Cl)(Cl)Cl</smiles>

$4,6,9$

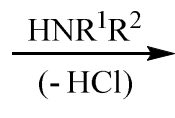

$\mathrm{HNR}^{1} \mathrm{R}^{2}$<smiles>[R]C(=O)NC(NC1=NCCCC1)=C(Cl)Cl</smiles>

11<smiles>[R]C(=O)N[C@]([Y])(NC1=NCCCC1)C(Cl)(Cl)Cl</smiles><smiles>[R]C(=O)NC(=NC1=NCCCC1)C(Cl)(Cl)Cl</smiles>

12<smiles>[R10]NC1=NC([Y])=N[Y]2CCCC[Y]21Cl</smiles>

$5,8,10$

Scheme 5. The proposed mechanism of $N$-hetaryl-2,2-dichloroacetamidines formation

It is more likely that the interaction of $N$-amidoalkylated aminoheterocycles with excess amines can take place under thermodynamic or kinetic control, which determines the nature of the reaction products. As it has already been noted ${ }^{20}$, the nature of the amide residue does not play a significant role in this process and does not affect the yield of the final reaction products. 
Further studies of the synthetic potential of obtained hetarylamidines continue, their results being published later.

\section{Conclusion}

After simple transformations of $\mathrm{N}$-amidoalkylated derivatives of 2-aminobenzimidazole, 2-aminobenztiazole and 2-amino-5-aryl-1,3,4-oxadiazole we have prepared corresponding $N$-hetaryl-2,2-dichloroacetamidines. The implemented transformations have greatly expanded the methods of synthesis of amidines with heterocyclic fragments and application of the recently discovered reaction.

\section{References}

1. Lindel T, Bräuchle L, Golz G and Böhrer G, Org Lett., 2007, 9(2), 283-286; DOI:10.1021/o10627348

2. Castellanos L, Duque C, Zea S, Espada A, Rodríguez J and Jiménez C, Org Lett., 2006, 8(21), 4967-4970; DOI:10.1021/o1062087k

3. Carlé J S and Christophersen C, J Org Chem., 1981, 46(17), 3440-3443; DOI:10.1021/jo00330a011

4. $\quad$ Fuch J R and Funk R L, Org Lett., 2005, 7(4), 677-680; DOI:10.1021/ol047532v

5. Kaneda M, J Antibiotics, 2002, 55(10), 924-928; DOI:10.7164/antibiotics.55.924

6. Bartsch A, Bross M, Spiteller P, Spiteller M and Steglich W, Angew Chem Int Ed., 2005, 44(19), 2957-2959; DOI:10.1002/anie.200500082

7. Greenhill J V and Lue P, Amidines and Guanidines in Medicinal Chemistry; Progress in medicinal chemistry, 1993, 30, 203-326; DOI:10.1016/S0079-6468(08)70378-3

8. Mitchell R E and Teh K L, Org Biomol Chem., 2005, 3, 3540-3543; DOI:10.1039/b509319h

9. Aly A A and Nour-El-Di A M, ARKIVOC, 2008, 1, 153-194.

10. Ishikawa T, Superbases for Organic Synthesis; John Wiley \& Sons: Chichester, 2009, 326.

11. Kapuscinski J, Biotech Histochem., 1995, 70(5), 220-233; DOI:10520295/95R24233

12. Sakamoto M, Miyazawa K and Tomimatsu Y, Chem Pharm Bull., 1977, 25(12), 3360-3365; DOI:10.1248/cpb.25.3360

13. Stoyanovich F M, Zakharov E P, Lysenko O V, Yarovenko V N and Krayushkin M M, Bull Acad Sciences USSR Chem Science, 1991, 40(1.2), 225-227.

14. Katsura Y, Inoue Y, Nishino S, Tomoi M, Itoh H and Takasugi H, Chem Pharm Bull., 1992, 40(6), 1424-1438; DOI:10.1248/cpb.40.1424

15. Raoudha A, Baccar B and Benkhoud M L, Phosphorus, Sulfur Silicon, 2002, 177(5), 1033-1040; DOI:10.1080/10426500211735

16. Hajri A and Abderrahim R, Phosphorus, Sulfur Silicon, 2011, 186(3), 520-525; DOI:10.1080/10426507.2010.506453

17. Raouafi N, Boujlel K and Benkhoud M L, Phosphorus, Sulfur Silicon, 2007, 182(4), 899-904; DOI:10.1080/10426500601088663

18. Raouafi N, Boujlel K and Benkhoud M L, Phosphorus, Sulfur Silicon, 2004, 179(7), 1387-1395; DOI:10.1080/10426500490463574

19. Raouafi N, Boujlel K and Benkhoud M L. Phosphorus, Sulfur, and Silicon, 2004, 179(12), 2471-2482; DOI:10.1080/10426500490485372

20. Zadorozhnii P V, Kiselev V V and Kharchenko A V, Visn Dnipropetr Univ Khim., 2014, 22(2), 31-38; DOI:10.15421/081412 
21. Zadorozhnii P V, Kiselev V V and Kharchenko A V, Synthesis of NitrogenContaining Heterocycles Based on $N$-(Isothiocyanatoalkyl)carboxamides. In: Novikov V, Ed., Modern Directions in Chemistry, Biology, Pharmacy and Biotechnology; Lviv Polytechnic Publishing House: Lviv, 2015, 212-219.

22. Chernous S Y, Okhtina O V, Kiselev V V and Kharchenko A V, Vopr Khim Khim Tekhnol., 2010, 6, 30-33.

23. Chernous S Y, Kharchenko A V, Rudenko E O, Okhtina O V, Aleksenko V A and Kiselev V V, Vopr khim khim Technol., 2004, 6, 45-47.

24. Zadorozhnii P V, Kiselev V V, Kharchenko A V and Okhtina O V, Vopr Khim Khim Tekhnol., 2013, 5, 9-11.

25. Chernous S Y, Kharchenko A V and Kiselev V V, Vopr. Khim. Khim. Tekhnol., 2007, 6, 59-62. 